\title{
Properties of Starches in Chinese Yam, Dioscorea oppsita Thunb. Irradiated with Proton Beam
}

\author{
Sang Kuk Kim ${ }^{1}$, Hong Jib Choi ${ }^{1}$, Kye Ryung Kim ${ }^{2}$ and Hak Yoon Kim ${ }^{3}$ \\ ${ }^{1}$ Division of Crop Science, Gyeongsangbuk-do Agricultural Research \& Extension Services, Daegu 702-708, Korea \\ ${ }^{2}$ Proton Engineering Frontier Project, KAERI, Daejeon 305-353, Korea \\ ${ }^{3}$ Department of Global Environment, Keimyung University, Daegu 704-701, Republic of Korea \\ The authors (Sang Kuk Kim and Hong Jib Choi) are equally contributed in this study
}

\begin{abstract}
The survival rate and thermal, crystal, and physicochemical properties of starches in chinese yam tubers irradiated to proton beam were determined. Survival rate was decreased with increased proton beam irradiation. Amylose content of D. opposita starches from different proton beam ranged from $13.2 \%$ to $17.8 \%$. D. opposita starch at 5 Gy showed the highest $\Delta H_{\text {gel }}$ values $(12.0 \mathrm{~J} / \mathrm{g})$ while $D$. opposita starch at $25 \mathrm{~Gy}$ showed the lowest values $(10.1 \mathrm{~J} / \mathrm{g})$. Several parameters such as PKV (peak viscosity), HPV (Hot peak viscosity) and CPV (Cooling peak viscosity) decreased with the increase in irradiation dose. The degrees of crystallinity of the D. opposita starches at 5, 10, 15, 20 and 25 Gy were 37.2, 38.3, 38.9, 39.2 and $39.9 \%$, respectively. It might be deduced that proton beam irradiation causes changes of starch, especially at high dose irradiation.
\end{abstract}

Key words - Dioscorea opposita, Chinese yam, Proton beam, Starch, DSC, RVA

\section{Introduction}

Mutation breeding is a useful method for crop improvement. The type of mutagenic treatment is an important factor to obtain successful results in mutation breeding. Radiation tool of food crops is one of the most common techniques for induction of crop mutations. Physical mutagens, such as gamma rays and $\mathrm{X}$-rays, have mainly been used to induce mutations, and many varieties have been released (Yamaguchi et al., 2009). The mutants are useful for developing new crop cultivars as well as for improving starch properties, especially in starchy crops such as rice, wheat, barley and potatoes ( $\mathrm{Yu}$ and Wang, 2007). Recently, proton beam including ion beams have attracted attention in the fields of plant breeding (Shikazono et al., 2003). A characteristic feature of ion beams is their ability to deposit high energy on a target, densely and locally, as opposed to low linear energy transfer (LET) radiation such as gamma rays and X-rays (Yang and Tobias, 1979; Tanaka, 1999). Mutation induction with ion beams, using various plants, has been attempted since the 2000s in Korea, the 1990s

*Corresponding author. E-mail : hykim@kmu.ac.kr in Japan (Tanaka, 1997). Until now, it has been demonstrated in Arabidopsis that ion beams induce mutations with high frequency and show a broad mutation and novel mutants have been obtained (Hase et al., 2000; Shikazono et al., 2003; Tanaka et al., 1997). Thus, the characteristics of ion beams have been gradually clarified, and ion beam irradiation has evolved as a new mutation method. However, in terms of the mutagen for mutation breeding, the characteristics of ion beams, especially in comparison to gamma rays and $\mathrm{X}$-rays, and the criterion of optimum irradiation dose for practical use have not been sufficiently clarified in Chinese yam. Recently, we investigated the effects of proton beams on changes of gel properties of Chinese yam including basic information on the physicochemical processing characteristics of Chinese yam flours.

\section{Materials and Methods}

Chinese yam (Dioscorea opposita Thunb. cv. Anwon) was exposed to proton beam (LET $1.7 \mathrm{keV} / \mu \mathrm{m}$ ) accelerated to 45 $\mathrm{MeV}$ with a dose of 5, 10, 15, 20, and $25 \mathrm{~Gy}$. The LET values of the beam were calculated at the surface of the tubers. After 
irradiation, fifty tubers $\left(\mathrm{vM}_{1}\right)$ from each irradiation treatment were sown into plastic pots to investigate the effects of proton beams on survival. After 30 day incubation, they were moved and grown into a greenhouse. Each tuber was used to determine survival rate $\left(\mathrm{LD}_{50}\right)$ and then harvested tubers $\left(\mathrm{vM}_{2}\right)$ derived from irradiated with proton beam were estimated to analyze properties of starch. Freeze-dried tubers were ground and sieved with a 100 mesh sifter. After sieving, powders were extracted with 100 and $85 \% \mathrm{MeOH}$. Starches were also extracted with SDS five times. Finally the starches were washed three times with $85 \% \mathrm{MeOH}$ and distilled water, respectively. Total starch was performed with the Megazyme kit according to AACC 76-13 (AACC, 2003). The absorption curves of starch and iodine complexes were measured by a UV/VIS spectrophotometer (Model Evolution 300, Thermo Electron Corporation, USA) at 700 to $500 \mathrm{~nm}$. A solution containing $2 \mathrm{mg}$ iodine and $20 \mathrm{mg}$ potassium iodate was added to $1 \mathrm{mg} \mathrm{NaOH}$-gelatinized and $\mathrm{HCl}$-neutralized starch, and made up to $25 \mathrm{ml}$. The wavelength at maximum absorption $(\lambda \max )$ and blue value (BV), absorbance at $680 \mathrm{~nm}$, were determined (Fujimoto et al., 1972). According to the method of Kainuma (1977), amperometric iodine titration of defatted starch was carried out at $1 \mathrm{~A}$ and $50 \mathrm{mV}$. The pasting properties of the starches ( $3 \mathrm{~g}, 14 \%$ moisture basis) in water $(25 \mathrm{ml})$ were determined using the Rapid Visco Analyzer (RVA, Newport Scientific Pty. Ltd., Narrabeen, Australia). Gelatinization of rice starch was performed on a Differential Scanning Calorimeter (DSC-SP, Rheometric Scientific, New Castle, DE, USA) and the instrument was calibrated with indium. Starch samples and distilled water $(1: 3, \mathrm{w} / \mathrm{w})$ were hermetically sealed in aluminum pans, held overnight, and heated from 30 to $120^{\circ} \mathrm{C}$ with $10^{\circ} \mathrm{C} / \mathrm{min}$ heating speed. An empty aluminum pan was used as reference. The collected data for tuber yield were analyzed by using SAS package for Duncan's multiple range tests.

\section{Results and Discussion}

The effect of proton beam irradiation on survival rates in Chinese yam plant was estimated (Fig. 1). Survival rate in Chinese yam tubers irradiated with proton beam ranged 14.5 to $96.5 \%$ depending on the dose of radiation. When proton

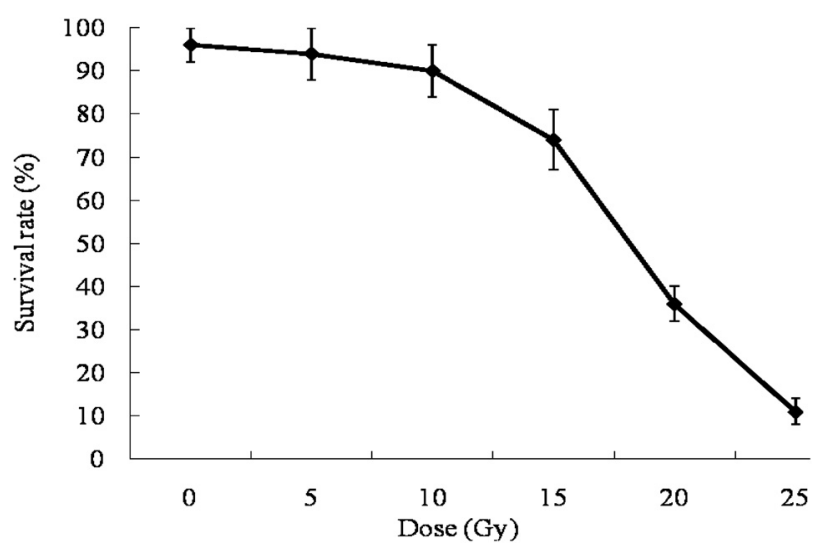

Fig. 1. Effect of proton ion beam doses on survival rate of Chinese yam tubers. Survival rate is defined as the number of seedlings from the irradiated tubers divided by the number of seedlings from non-irradiated tubers. Vertical bars indicate $\mathrm{SE}(\mathrm{n}=3)$.

beam intensity was increased, survival rate was slightly decreased until $15 \mathrm{~Gy}$, however, it decreased rapidly at 20 and 25 Gy. It was assumed that 50\% lethal dose was ranged from above $15 \mathrm{~Gy}$ to below $20 \mathrm{~Gy}$ with proton beams. Physicochemical properties of flours were also determined from the tubers irradiated with proton beam (Table 2). Maximum absorption $(\lambda \max )$ degree for tuber flours irradiated with different doses was slightly increased with elevated proton beam doses. Blue value was increased as the dose of proton beam irradiation increased. Starch content was not changed by proton beam irradiation as compared to the control. Unlike a change of starch content, amylose content showed that highest proton beam irradiation leaded to significant increase. In cereal crops, amylose content was reduced with increasing gamma ray (Bao et al., 2005).

Table 2 shows gelatinization properties of starch determined by DSC. DSC parameters recorded onset temperature (To), peak temperature $(\mathrm{T} p)$, conclusion temperature $(\mathrm{T} c)$, gelatinization range ( $\mathrm{R}, \mathrm{T} c$ - $\mathrm{T} o$ ), enthalpy of gelatinization $(\Delta H)$, and peak height index (PHI). The gelatinization temperature and enthalpies associated with gelatinization endotherms was caused by increasing proton beam irradiation. Onset temperature in tuber starches with 5 to $25 \mathrm{~Gy}$ was ranged 73.2 to $74.6{ }^{\circ} \mathrm{C}$. Onset temperature was lower in starches extracted from proton beam irradiation than in the control. Otherwise, peak temperature shows opposite results against increasing proton 
Table 1. Effects of proton beams on wavelength at maximum absorption ( $\lambda \max )$, blue value of proton beams on starch and amylose contents in Chinese yam flours.

\begin{tabular}{ccccc}
\hline \hline Dose $($ Gy) & $\begin{array}{c}\lambda \max \\
(\mathrm{nm})\end{array}$ & $\begin{array}{c}\text { Blue value } \\
\text { (at } 680 \mathrm{~nm})\end{array}$ & $\begin{array}{c}\text { Starch content } \\
(\%)\end{array}$ & $\begin{array}{c}\text { Amylose content } \\
(\%)\end{array}$ \\
\hline 0 & 591 & 0.22 & 84.7 & $13.2 \mathrm{~d}$ \\
5 & 603 & 0.27 & 84.6 & $13.6 \mathrm{~cd}$ \\
10 & 611 & 0.29 & 85.7 & $14.1 \mathrm{c}$ \\
15 & 613 & 0.35 & 85.4 & $15.2 \mathrm{bc}$ \\
20 & 613 & 0.37 & 85.5 & $17.0 \mathrm{~b}$ \\
25 & 618 & 0.38 & 85.6 & $17.8 \mathrm{a}$ \\
\hline
\end{tabular}

Different letters within each column indicate significant differences $(p<0.05)$.

Table 2. Effects of proton beam irradiation on thermal properties of Chinese yam flours determined by Differential Scanning Calorimeter (DSC).

\begin{tabular}{|c|c|c|c|c|c|c|}
\hline \multirow{2}{*}{ Dose (Gy) } & \multicolumn{6}{|c|}{ Gelatinization parameters } \\
\hline & $\mathrm{To}\left({ }^{\circ} \mathrm{C}\right)$ & $\mathrm{T} p\left({ }^{\circ} \mathrm{C}\right)$ & $\mathrm{T} c\left({ }^{\circ} \mathrm{C}\right)$ & $\Delta H_{\text {gel }}(\mathrm{J} / \mathrm{g})$ & PHI & $R$ \\
\hline 0 & $75.1 \mathrm{a}$ & $84.9 \mathrm{~d}$ & $92.4 \mathrm{~b}$ & 12.4 & 0.72 & $17.3 \mathrm{a}$ \\
\hline 5 & $74.6 b$ & $85.5 \mathrm{c}$ & $92.3 b$ & 12.0 & 0.78 & $15.4 \mathrm{~b}$ \\
\hline 10 & $74.3 b$ & $85.8 \mathrm{c}$ & $92.5 b$ & 11.6 & 0.91 & $12.8 \mathrm{c}$ \\
\hline 15 & $73.7 \mathrm{c}$ & $86.7 \mathrm{~b}$ & $92.4 \mathrm{~b}$ & 11.3 & 1.06 & $10.7 \mathrm{~d}$ \\
\hline 20 & $73.5 \mathrm{c}$ & $87.5 \mathrm{a}$ & $93.0 \mathrm{a}$ & 10.5 & 1.08 & $9.7 \mathrm{e}$ \\
\hline 25 & $73.2 \mathrm{~d}$ & $87.9 \mathrm{a}$ & $92.2 \mathrm{~b}$ & 10.1 & 1.33 & $7.6 f$ \\
\hline
\end{tabular}

Different letters within each column indicate significant differences $(p<0.05)$. To, onset temperature; T $p$, peak temperature; T $c$, conclusion temperature; R, gelatinization range (Tc-To); $\Delta H$, enthalpy of gelatinization (based on starch dry weight); PHI, peak height index $\Delta$ $H \mathrm{gel} /(\mathrm{T} p-\mathrm{T} o)$.

Table 3. Effects of proton beams on pasting properties of Chinese yam flours determined by Rapid Visco Analyser.

\begin{tabular}{|c|c|c|c|c|c|c|c|}
\hline \multirow{2}{*}{ Dose (Gy) } & \multirow{2}{*}{$\begin{array}{l}\text { Pasting time } \\
\text { (min.) }\end{array}$} & \multirow{2}{*}{$\begin{array}{l}\text { Pasting temp. } \\
\left({ }^{\circ} \mathrm{C}\right)\end{array}$} & \multicolumn{5}{|c|}{ Viscosity (RVU) } \\
\hline & & & PKV & HPV & $\mathrm{CPV}$ & Breakdown & Setback \\
\hline 0 & 4.9 & $94.4 \mathrm{a}$ & $3,811 \mathrm{a}$ & $3,018 \mathrm{a}$ & $4,193 \mathrm{a}$ & $793 a$ & $382 \mathrm{a}$ \\
\hline 5 & 4.8 & $94.1 \mathrm{a}$ & $3,769 \mathrm{a}$ & $3,011 \mathrm{a}$ & $3,975 \mathrm{a}$ & $758 b$ & $206 \mathrm{c}$ \\
\hline 10 & 4.6 & $94.2 \mathrm{a}$ & $3,617 b$ & $2,973 b$ & $3,934 \mathrm{a}$ & $644 d$ & $317 b$ \\
\hline 15 & 4.5 & $93.4 b$ & $3,503 \mathrm{c}$ & $2,894 b$ & $3,261 b$ & $609 \mathrm{e}$ & $-242 d$ \\
\hline 20 & 4.5 & $91.7 \mathrm{c}$ & $3,419 \mathrm{~d}$ & $2,753 \mathrm{c}$ & $3,201 b$ & $666 c$ & $-218 c$ \\
\hline 25 & 4.4 & $90.6 \mathrm{~d}$ & $3,374 \mathrm{e}$ & $2,705 d$ & $3,118 \mathrm{c}$ & $669 \mathrm{c}$ & $-256 \mathrm{e}$ \\
\hline
\end{tabular}

Data are means of three determinations. Different letters within each column indicate significant differences $(p<0.05)$.

beam irradiation. The more proton beam irradiation was increased the more peak temperature in tuber starches was also increased. The enthalpies of gelatinization in starches reflect the loss of molecular order (Cooke and Gidley, 1992) and gelatinization temperature is also considered a parameter of crystallite perfection (Tester and Morrison, 1990). The enthalpies of gelatinization in tuber starches were slightly reduced by increasing proton beam doses as compared to the control. Gelatinization range was significantly reduced by elevated proton beam doses. Gelatinization temperature range in tuber starch irradiated with $25 \mathrm{~Gy}$ was $9.7^{\circ} \mathrm{C}$ lower than that of control. With the analysis of RVA, seven major parameters of starch pasting properties, peak viscosity (PKV), hot pasting viscosity (HPV), cool pasting viscosity (CPV), setback (CPV minus PKV), breakdown (PKV minus HPV), peak time, and pasting time were significant decreased with the increasing 
Table 4. Changes of X-ray diffraction data of Chinese yam starches as affected by different proton beam dose.

\begin{tabular}{rccccc}
\hline \hline \multirow{2}{*}{$\begin{array}{c}\text { Dose } \\
(\mathrm{Gy})\end{array}$} & $\begin{array}{c}\text { Crystallinity } \\
(\%)\end{array}$ & $6^{\circ}$ & \multicolumn{3}{c}{ Diffraction peaks at $2 \theta$ values } \\
\cline { 3 - 6 } & $(\%)$ & 6.2 & $17^{\circ}$ & $18^{\circ}$ & $23^{\circ}$ \\
\hline 5 & $34.4 \mathrm{a}$ & 6.4 & 18.1 & 23.0 & 23.0 \\
10 & $37.2 \mathrm{~b}$ & 6.0 & 16.5 & 18.7 & 23.1 \\
15 & $38.3 \mathrm{c}$ & 6.3 & 16.3 & 18.4 & 23.3 \\
20 & $38.9 \mathrm{c}$ & 6.3 & 16.4 & 18.8 & 23.1 \\
25 & $39.2 \mathrm{~d}$ & 6.1 & 16.3 & 18.3 & 23.4 \\
\hline
\end{tabular}

dose (Table 3).

The pasting time in tuber starch irradiated with proton beam was 0.5 min shorter than that of the control. Pasting temperature ranged 90.6 to $94.1^{\circ} \mathrm{C}$. Pasting temperature of tuber starch was decreased with increasing proton beam. Peak viscosity (PKV), hot pasting viscosity (HPV), cool pasting viscosity (CPV), setback (CPV minus PKV), breakdown (PKV minus HPV), peak time, and pasting time were correlated negatively with increasing proton beam dose. These changes in pasting properties were also referred to the breakage of starch granules caused by proton beam irradiation ( $\mathrm{Yu}$ and Yang, 2007). The crystallinity of tuber starch was significantly affected by increasing proton beam dose (Table 4). The crystallinity degree of tuber starch irradiated with proton beam ranged from 37.2 to $39.9 \%$. Crystallinity of irradiated starches was 2.8 to $5.5 \%$ higher than that of the control. Increased crystallinity of starches determined by X-ray diffraction techniques has been reported in wheat (MacArthur and D'Appolonia, 1984) and rice (Wootton et al., 1988) starches. It was also reported that the decrease of $\Delta H$ in irradiated potato starch induced a decrease in crystallinity (Ciesla and Eliasson, 2002). Consequently, the proton beam application causes a reduction viscosity of Chinese yam starch. It can be concluded from the present study that proton beam irradiation causes physicochemical changes of starch properties in Chinese yam.

\section{Literature Cited}

AACC. 2003. Approved Methods. Method number 76-13. Total starch assay procedure (Megazyme amyloglucosidase/ alpha-amylase method). St. Paul, Minnesota: AACC.
Bao, J., Z. Ao and J. L. Jane. 2005. Characterization of physical properties of flour and starch obtained from gamma-irradiated white rice. Starch 57:480-487.

Ciesla, K. and A.C. Eliasson 2002. Influence of gamma radiation on potato starch gelatinization studied by differential scanning calorimetry. Radiat. Phys. Chem. 64:137-148.

Cooke, D. and M.J. Gidley. 1992. Loss of crystalline and molecular order during starch gelatinization: Origin of the enthalpic transition. Carbohydrate Res. 227:103-112.

Fujimoto, S., T. Nagahama and M. Kanie. 1972. Changes in contents and chain length of amylose of sweet potato starch with development of the granules. Nippon Nogeikagaku Kaishi 46:577-583

Kainuma, K. 1977. Handbook of Starch Science: In Nikuni J. et al. (eds.). Asakara Shoten, Japan. pp. 202.

Hase, Y., T. Tanaka, T. Baba and H. Watanabe. 2000. FRL1 is required for petal and sepal development in Arabidopsis. Plant J. 24:21-32.

MacArthur, L.A. and B. L. D’Appolonia. 1984. Gamma radiation of wheat. II. Effects of low-dosage radiations on starch properties. Cereal Chem. 61:321-326.

Shikazono, N., Y. Yokota, S. Kitamura, C. Suzuki, H. Watanabe, S. Tano and A. Tanaka. 2003. Mutation rate and novel $t t$ mutants of Arabidopsis thaliana induced by carbon ions. Genetics 163:1449-1455.

Tanaka, A. 1999. Mutation induction by ion beams in Arabidopsis. Gamma Field Symp. 38:19-27.

Tanaka, A., A. Sakamoto, Y. Ishigaki, O. Nikaido, G. Sun, Y. Hase, N. Shikasono, S. Tano and H. Watanabe. 2002. An ultraviolet-B-resistant mutant with enhanced DNA repair in Arabidopsis. Plant Physiol. 129:64-71.

Tanaka, A., S. Tano, T. Chantes, Y. Yokota, N. Shikazono and H. Watanabe. 1997. A new Arabidopsis mutant induced by ion beams affects flavonoid synthesis with spotted pigmen- 
tation in testa. Genes Genet. Syst. 72:141-148.

Tester, R.F. and W.R. Morrison. 1990. Swelling and gelatinization of cereal starches. II. Waxy rice starches. Cereal Chem. 67:558-563.

Wootton, M., H. Djojonegoro and R. Driscoll. 1988. The effect of gamma-irradiation on the quality of Australian rice. J. Cereal Sci. 7:309-315.

Yamaguchi, H., Y. Hae, A. Tanaka, N. Shikazono, K. Degi, A. Shimizu and T. Morishita. 2009. Mutagenic effects of ion beam irradiation on rice. Breed. Sci. 59:169-177.

Yang, T.C. and C.A. Tobias. 1979. Potential use of heavy-ion radiation in crop improvement. Gamma Field Symp. 18: 141-154.

Yu, Y, and J. Wang. 2007. Effect of $\gamma$-ray irradiation on starch granule structure and physicochemical properties of rice. Food Res. Intern. 40:297-303.

(Received 25 February 2011 ; Accepted 21 June 2011) 